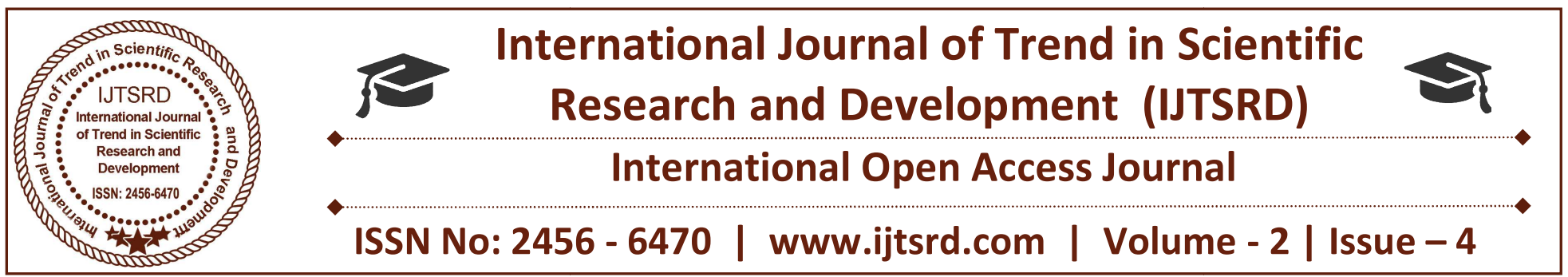

\title{
Green Synthesis of ZnO Nanoparticles using Jasminum Fluminense Leaf Extract and its Spectral and Optical Characterization Studies
}

\author{
Dr. S. Amudha \\ Assistant Professor, Department of Physics, \\ S.D.N.B. Vaishnav College for Women, Chennai, Tamil Nadu, India
}

\begin{abstract}
\end{abstract}
The main objective of the present study is to deal with the green synthesis of Zinc Oxide [ $\mathrm{ZnO}$ ] nanoparticles utilizing aqueous leaf extract of Jasminum Fluminense.' Zinc acetate $\left[\mathrm{Zn}\left(\mathrm{O}_{2} \mathrm{CCH}_{3}\right)_{2}\left(\mathrm{H}_{2} \mathrm{O}\right)_{2}\right]$ and sodium hydroxide $[\mathrm{NaOH}]$ were used as starting materials and Jasminum Fluminense [Nithyamalli] leaf extract is used as precursor in the synthesis of $\mathrm{ZnO}$ nanoparticles. The resultant nanopowder was characterized by using Ultraviolet [UV] - Visible Spectroscopy, Fourier Transform T Infrared Spectroscopy [FTIR] and Transmission Electron Microscopic [TEM] studies. Formation of $\mathrm{ZnO}$ nanoparticles has been confirmed by UV-visible spectroscopy and the TEM analysis spectacles that the synthesized $\mathrm{ZnO}$ nanoparticles are of face centered cubic (fcc) structure and the size is found to be around $20 \mathrm{~nm}$. FTIR spectral analysis indicated the leaf extract acts as the reducing and capping agents on the surface of $\mathrm{ZnO}$ nanoparticles. This simplistic and green approach may provide a useful tool to hefty extent in the synthesis of $\mathrm{ZnO}$ nanoparticles. These synthesized nanostructures illustrate novel applications in many fields such as cosmetics, optoelectronics, sensors, transducers and biomedical science because it is environmentally friendly and does not involve any harmful substances.

Keywords: Leaf extract, Nanopowder, Jasminum Fluminense and Biomedical science

\section{INTRODUCTION}

In recent years the growth of hazardless free metal nanoparticles has become a great challenge. Different metal nanoparticles can be synthesized but among

them Zinc Oxide $(\mathrm{ZnO})$ plays a vital role in chemical industries due to its anti-corrosive and anti-bacterial activities. Metal nanoparticles can be prepared by both physical and chemical methods such as UV irradiation, microwave irradiation, chemical reduction, photochemical method, electron irradiation and sonoelectrochemical method [1]. But these methods are costly, labor intensive and hazardous to environment as well as living organisms and in order to eliminate this we need an alternative, environmentally friendly, cost-effective and safest approach [2]. So green approach of nanoparticle synthesis has gained great attention among scientists and literature review divulges that leaves are generally used for the synthesis of metal nanoparticles because they act as both reducing and stabilizing agent.

Generally nanoparticles are the cluster of atoms in nanometer range. There are two types of nanoparticles namely metal and metal oxide nanoparticles. Both of them are very important but metal oxide nanoparticle such as $\mathrm{CuO}, \mathrm{TiO}_{2}$ and $\mathrm{ZnO}$ have semiconductor properties. Now-a-days $\mathrm{ZnO}$ nanoparticle has gained great attention among researchers owing to its different characteristics such as catalysis, electrical conductivity and cytotoxicity [3]. The biological synthesis of $\mathrm{ZnO}$ nanoparticles from leaves such as Moringa oleifera, Lemon grass, Coriandrum sativum and Catharanthus roseus has already been reported [4-8]. In our point of view, $\mathrm{ZnO}$ nanoparticles from Jasminum Fluminense using Zinc acetate and Sodium hydroxide as starting material was reported for the first time. Commonly, $\mathrm{ZnO}$ is a metal oxide semiconductor belonging to II-VI group having large 
exciton binding energy of $60 \mathrm{meV}$ and wide band gap of about $3.4 \mathrm{eV}$. It has wide application in solar cells, gas sensors, ceramics, catalysts and used as an additive in paints, cosmetics, plastics, rubber manufacturing, electronics, pharmaceuticals, agriculture and aquaculture [9]. The plant Jasminum Fluminense belonging to the Olive family called Oleaceae and it contains about 200 species native to tropical and warm temperate regions of Eurasia, Australasia and Oceania. It is a climber plant belonging to dicotyledon and angiosperm group. The main aim of the present study is to synthesize Zinc Oxide $(\mathrm{ZnO})$ nanoparticles using aqueous leaf extract of Jasminum Fluminense and to evaluate the structure by various characterization tools such as Ultraviolet [UV] - Visible Spectroscopy, Fourier Transform Infrared Spectroscopy [FTIR] and Transmission Electron Microscopic [TEM] studies.

\section{MATERIALS AND METHODS}

\subsection{Materials Required}

Zinc acetate $\left[\mathrm{Zn} \quad\left(\mathrm{O}_{2} \mathrm{CCH}_{3}\right)_{2}\left(\mathrm{H}_{2} \mathrm{O}\right)_{2}\right]$, Sodium hydroxide $[\mathrm{NaOH}]$ pellet and glasswares were purchased from Merck and used as received and Jasminum Fluminense leaves were collected from SDNB Vaishnav College Campus. The leaves and all the glasswares were thoroughly washed with double distilled water before use.

\subsection{Preparation of Jasminum}

Fluminense Leaf Extract

Fresh leaves of Jasminum Fluminense about $10 \mathrm{~g}$ were collected and washed several times with tap water and then with distilled water and cut into small pieces. These leaves were boiled with $100 \mathrm{ml}$ of double distilled water at $60^{\circ} \mathrm{C}$ for about 30 minutes. After boiling, color of the solution changes to light brown color and it was cooled at room temperature. This extract was filtered through Whatman Number-1 filter paper and stored in refrigerator for further characterization studies.

\subsection{Green Synthesis of $\mathrm{ZnO}$ Nanoparticles}

For the synthesis of $\mathrm{ZnO}$ nanoparticles $1 \mathrm{mM}$ Zinc acetate $\left[\mathrm{Zn}\left(\mathrm{O}_{2} \mathrm{CCH}_{3}\right)_{2}\left(\mathrm{H}_{2} \mathrm{O}\right)_{2}\right]$ was dissolved in 50 $\mathrm{ml}$ of distilled water and kept in stirrer for $1 \mathrm{hr}$ respectively. Then $1 \mathrm{mM}$ of Sodium hydroxide $[\mathrm{NaOH}]$ Pellets was dissolved in $20 \mathrm{ml}$ of distilled water and kept in stirrer for $1 \mathrm{hr}$ respectively. Then 25 $\mathrm{ml}$ of Jasminum Fluminense leaf extract was added drop wise to the above mixture and continuously stirred at $50^{\circ} \mathrm{C}$ for another $1 \mathrm{hr}$ until the colloidal solution is obtained. The colour of the resultant solution changes to light pale yellow colour which confirms the presence of $\mathrm{ZnO}$ nanoparticles. The precipitate was centrifuged at $10000 \mathrm{rpm}$ at $50{ }^{\circ} \mathrm{C}$ for $20 \mathrm{~min}$ and powdered specimen was collected. This yellow coloured sample was dried using a hot air oven operating at $70{ }^{\circ} \mathrm{C}$ for $2 \mathrm{~h}$ and crushed using ceramic mortar and pestle to get fine Zinc Oxide ( $\mathrm{ZnO})$ nanoparticles and stored in air-tight bottles for further characterization studies [10].

\subsection{Characterization}

The optical properties of synthesized $\mathrm{ZnO}$ nanoparticles were investigated using UV-visible 8500 spectrophotometer in the wavelength range 250 $1000 \mathrm{~nm}$. The FTIR spectra were recorded using $\mathrm{KBr}$ pellet method by FTIR Spectrophotometer (Bruker, Tensor 27) at the wave number resolution of $1 \mathrm{~cm}^{-1}$ and with a total number of scans as 32 in the range $4000-650 \mathrm{~cm}^{-1}$ on the transmittance mode. The morphology was observed by Transmission Electron Microscopy using Hitachi Model TEM.

\section{RESULTS AND DISCUSSION}

\subsection{UV-visible Spectroscopic Results}

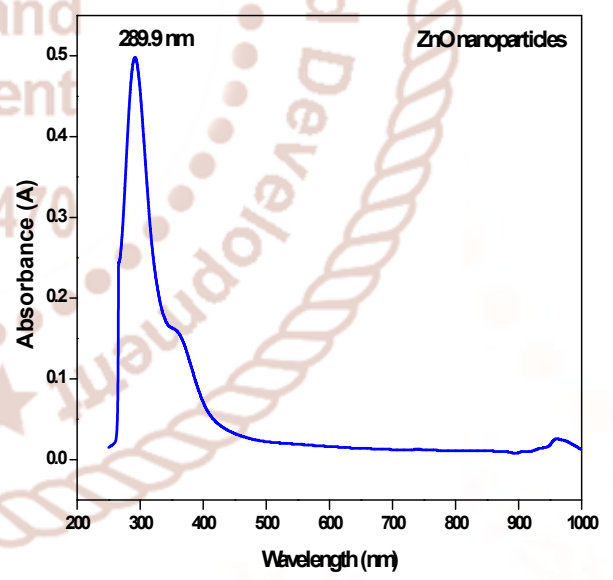

Fig. 1 UV-visible spectrum of biosynthesized ZnO nanoparticles

Figure 1 shows the UV-visible absorption spectrum obtained for the synthesized Zinc Oxide ( $\mathrm{ZnO})$ nanoparticles recorded between the range $250-1000$ $\mathrm{nm}$. It is known that the $\mathrm{ZnO}$ nanoparticles have free electrons due to which Surface Plasmon Resonance (SPR) absorption band appear at $289.9 \mathrm{~nm}$. This absorption peak indicates the reduction of $\mathrm{Zn}^{2+}$ ions in the reaction medium which authenticates the formation of $\mathrm{ZnO}$ nanoparticles [4, 11]. No other peaks have been observed which confirms the 
presence of $\mathrm{ZnO}$ nanoparticles only. From the UV- $2856 \mathrm{~cm}^{-1}$ are due to $\mathrm{C}-\mathrm{H}$ stretching vibration [12]. visible graph the energy band gap is calculated using The band at $1750 \mathrm{~cm}^{-1}$ corresponds to $\mathrm{C}=\mathrm{O}$ stretching the formula

$$
E_{g}=\frac{1240}{\lambda_{\max }} \mathrm{eV}
$$

The energy band gap value is found to be $4.28 \mathrm{eV}$ which is more than pure $\mathrm{ZnO}$ nanoparticles i.e., 3.4 $\mathrm{eV}$.

\subsection{FTIR Spectral Analysis of ZnO Nanoparticles}

FTIR spectral analysis was carried out to find the functional groups present in $\mathrm{ZnO}$ nanoparticles and the FTIR spectra of $\mathrm{ZnO}$ nanoparticles is shown in Figure 2. The spectrum portraying band at 2924 and

[9] whereas the peak at $1561 \mathrm{~cm}^{-1}$ is attributed to asymmetric stretching band from -COO- groups of acetate ions respectively [13]. The intense vibrational band around $1401 \mathrm{~cm}^{-1}$ is assigned to symmetric stretching of carbonyl side group [14] whereas the band at 922 and $858 \mathrm{~cm}^{-1}$ may correspond to $\mathrm{O}-\mathrm{H}$ bending vibrations of carboxylic acid [15] and $\mathrm{C}-\mathrm{H}$ bending vibration [10]. The vibrational band observed at 708 and $666 \mathrm{~cm}^{-1}$ corresponds to $-\mathrm{C}=\mathrm{C}-\mathrm{H}$ [16] and $\mathrm{M}-\mathrm{O}$ stretching of $\mathrm{ZnO}$ [17] nanoparticles. The FTIR spectra thus demonstrates the structural changes taking place in the $\mathrm{ZnO}$ nanoparticles and Jasminum Fluminense leaf extract by the co-ordination of $\mathrm{O}-\mathrm{H}$, $\mathrm{C}-\mathrm{H}, \mathrm{C}=\mathrm{O}$ and $-\mathrm{COO}$ - bonds.

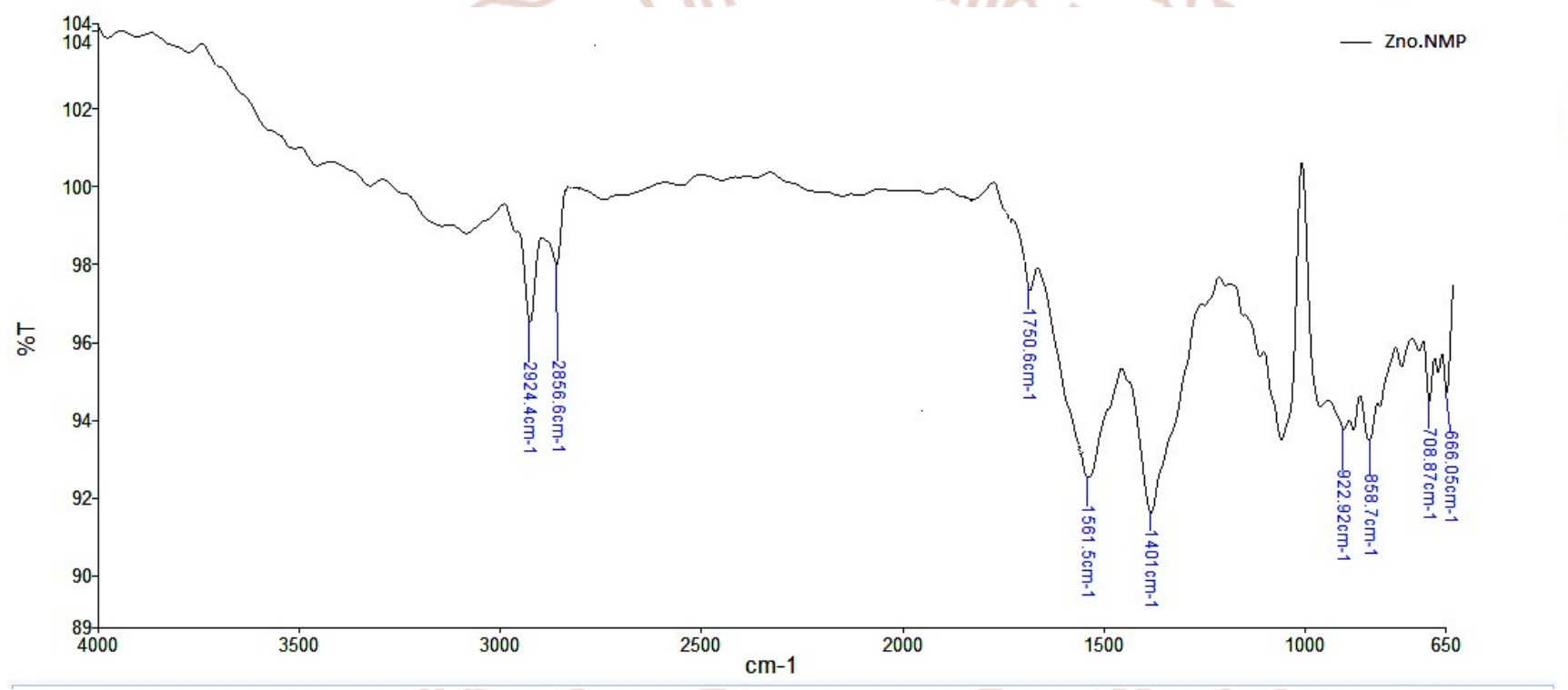

Fig. 2 FTIR spectra obtained for biosynthesized ZnO nanoparticles

\subsection{TEM Results}

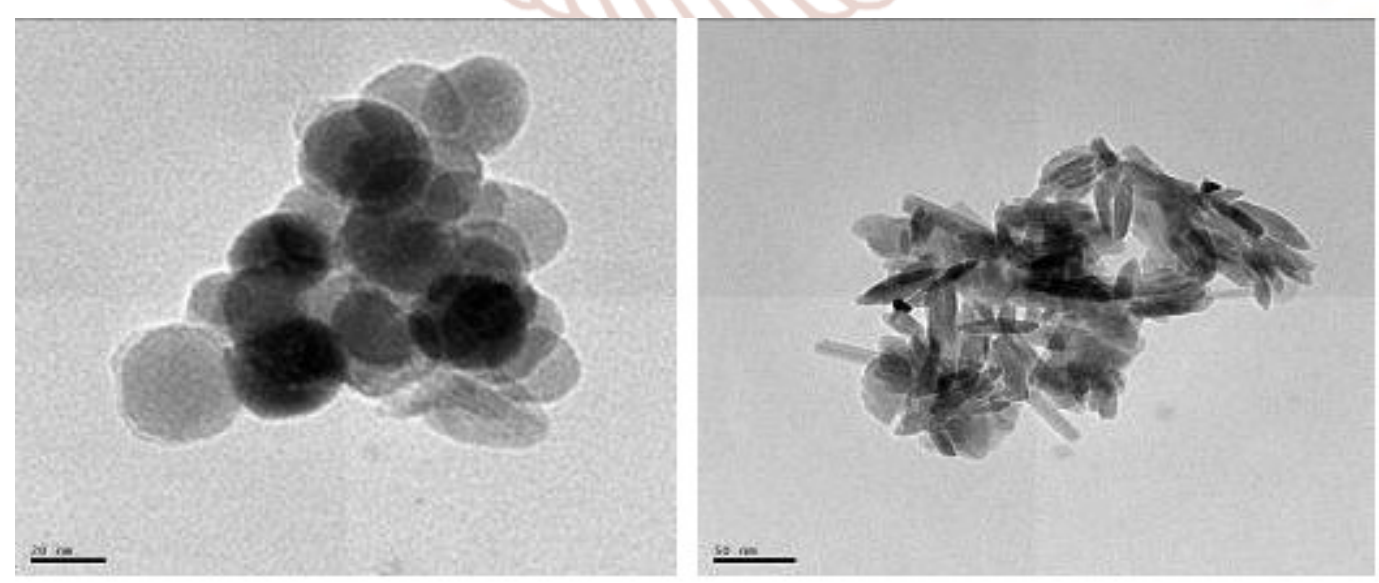

Fig. 3 TEM image of synthesized $\mathrm{ZnO}$ nanoparticles at different magnifications 
The morphology and size of Zinc Oxide ( $\mathrm{ZnO})$ nanoparticles examined using Transmission Electron Microscopic (TEM) analysis as shown in Figure 3. These images depicts that the nanoparticles are hexagonal, rod shaped and some of them are spherical at different magnifications. These spherical structures indicate the presence of amorphous nature of $\mathrm{ZnO}$ nanoparticles [2]. The average diameter of the $\mathrm{ZnO}$ nanoparticle is found to be $20 \mathrm{~nm}$ which is correlated with the earlier reports [18].

\section{CONCLUSIONS}

In this present study eco-friendly, easy synthesis, lowcost, non-hazardous, organically effective and innovative approach of the biosynthesized $\mathrm{ZnO}$ nanoparticles using Jasminum Fluminense leaf extract have been reported. The phytochemicals present in the leaf extract acts as a biological stabilizing and reducing agent for the synthesis of metal oxide nanoparticles. The presence of $\mathrm{ZnO}$ nanoparticles was confirmed using UV-visible, FTIR and TEM studies. The absorption band observed at $289.9 \mathrm{~nm}$ with an energy band gap of $4.28 \mathrm{eV}$ is confirmed by UVvisible spectroscopic studies. FTIR result confirms the presence of functional groups in $\mathrm{ZnO}$ nanoparticles. The particle size was found to be around $20 \mathrm{~nm}$ with hexagonal Wurtzite structure as evidenced from TEM results. Thus, it is exemplified that the $\mathrm{ZnO}$ nanoparticles synthesized in this research work acts as a promising candidate for future biological applications.

\section{REFERENCES}

1) Y.Y. Loo, B.W. Chieng, M. Nishibuchi, S. Radu, "Synthesis of silver nanoparticles by using tea leaf extract from Camellia Sinensis", Int. J. Nanomed., Vol. 7, (2012), 4263-4267.

2) J. Suresh, G. Pradheesh, V. Alexramani, M. Sundrarajan, S.I. Hong, "Green synthesis and characterization of zinc oxide nanoparticle using insulin plant (Costus pictus D. Don) and investigation of its antimicrobial as well as anticancer activities", Adv. Nat. Sci.: Nanosci. Nanotechnol., Vol. 9, (2018), 015008.

3) L.F.A. Anand Raj, E. Jayalakshmy, "Effect of zinc oxide nanoparticle produced by Zingiber Officinale against pathogenic bacteria”, J. Chem. Pharmaceutical Sci., Vol. 8, (2015), Issue 1.

4) C. Thirunavukkarasu, R. Archana, S. Sharmila, B. Janarthanan, J. Chandrasekaran, "Preparation and characterization of zno nanoparticles using Moringa Oleifera extract by green synthesis method", Asian Journal of Phytomedicine and Clinical Research, Vol. 4, (2016), 121 - 132.

5) T.S. Anvekar, V. Rajendra Chari, H. Kadam, "Green synthesis of $\mathrm{ZnO}$ nanoparticles, its characterization and application", Mater. Sci. Res. India, Vol.14, (2017), 153-157.

6) S.S.M. Hassan, W.I.M.E. Azab, H.R. Ali, M.S.M. Mansour, "Green synthesis and characterization of $\mathrm{ZnO}$ nanoparticles for photocatalytic degradation of anthracene", Adv. Nat. Sci.: Nanosci. Nanotechnol., Vol. 6, (2015), 045012.

7) S. Goutam, A.K.Yadav, A. Jyoti Das, “Coriander extract mediated green synthesis of zinc oxide nanoparticles and their structural, optical and antibacterial properties", J. Nanosci. Tech., Vol. 3, (2017), 249-252.

8) G. Bhumi, N. Savithramma, "Biological synthesis of zinc oxide nanoparticles from Catharanthusroseus G. Don. Leaf extract and validation for antibacterial activity", Int. J. Drug Dev. \& Res., Vol. 6, (2014), 208-214.

9) S. Narendhran, R. Sivaraj, "Biogenic $\mathrm{ZnO}$ nanoparticles synthesized using $L$. aculeata leaf extract and their antifungal activity against plant fungal pathogens", Bull. Mater. Sci., Vol. 39, (2016), 1-5.

10) J. I7 Santhoshkumar, S.Venkat Kumar, S. Rajeshkumar, "Synthesis of zinc oxide nanoparticles using plant leaf extract against urinary tract infection pathogen", Resource Efficient Technologies, Vol. 3, (2017), 1-7.

11) S. Kavitha, M. Dhamodaran, Rajendra Prasad, M. Ganesan, "Synthesis and characterisation of zinc oxide nanoparticles using terpenoid fractions of Andrographis paniculata leaves", Int. Nano Lett. Vol. 7, (2017), 141-147.

12) A. Geetha, R. Sakthivel, J. Mallika, R. Kannusamy, R. Rajendran, "Green synthesis of antibacterial zinc oxide nanoparticles using biopolymer Azadirachta indica Gum", Oriental J. Chem., Vol. 32, (2016), 955-963.

13) D.S. Chauhan , C.S.A. Gopal, D. Kumar, N. Mahato, M.A. Quraishi, M.H. Cho, "Microwave induced green synthesis of nanostructured $\mathrm{ZnO}$ as promising antibacterial agent", Glob. J. Nanomed., Vol. 2, (2017), 001-005. 
14) C. Joel, M. Sheik Muhideen Badhusha, "Green synthesis of $\mathrm{ZnO}$ nanoparticles using Phyllanthus embilica stem extract and their antibacterial activity", Der Pharmacia Lettre, Vol. 8, (2016), 218-223.

15) S.P. Rajendran, K. Sengodan, "Synthesis and characterization of zinc oxide and iron oxide nanoparticles using Sesbania grandiflora leaf extract as reducing agent", J. Nanosci., (2017), Article ID: 8348507.

16) S.Vennila, S.S. Jesurani, "Eco-friendly green synthesis and characterization of stable $\mathrm{ZnO}$ nanoparticle using small Gooseberry fruits extracts", Int. J. Chem. Tech. Res., Vol. 10, (2017), 271-275.

17) N. Sundaramurthy, C. Parthiban, "Biosynthesis of copper oxide nanoparticles using Pyrus Pyrifolia leaf extract and evolve the catalytic activity", Int. Res. J. Eng. Tech., Vol. 2, (2015), 332-338.

18) Shamsuzzaman, A. Mashrai, H. Khanam, R.N. Aljawfi, Biological synthesis of $\mathrm{ZnO}$ nanoparticles using $\mathrm{C}$. albicans and studying their catalytic performance in the synthesis of steroidal pyrazolines", Arabian J. Chem., Vol. 10, (2017), S1530-S1536.

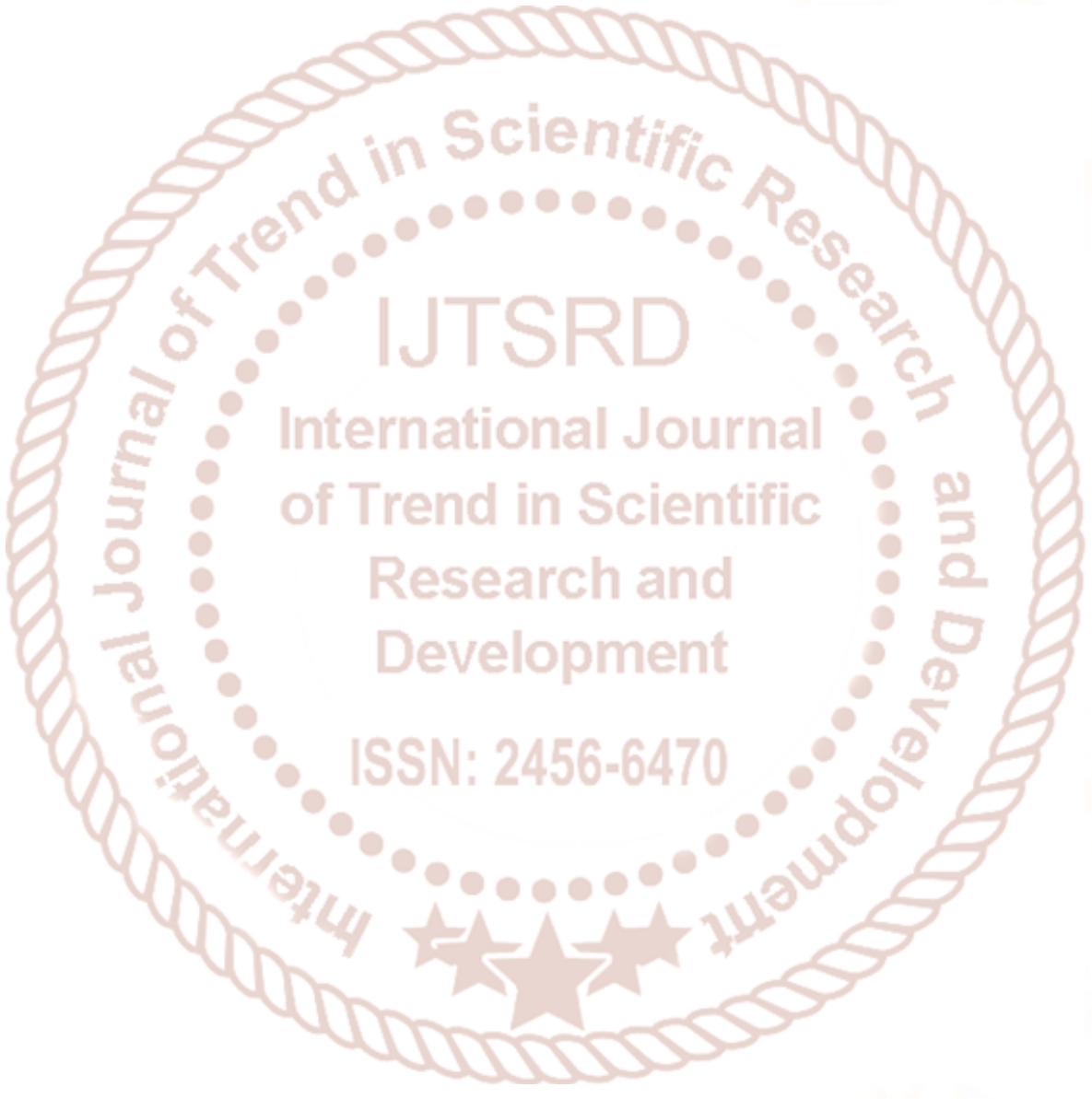

